Review

\title{
A brief review of para-xylene oxidation to terephthalic acid as a model of primary $\mathrm{C}-\mathrm{H}$ bond activation
}

\author{
Nor Aqilah Mohd Fadzil, Mohd Hasbi Ab. Rahim*, Gaanty Pragas Maniam \\ Faculty of Industrial Sciences \& Technology, Universiti Malaysia Pahang, Lebuhraya Tun Razak, 26300 Gambang Kuantan, Pahang, Malaysia
}

\section{A R T I C L E I N F O}

Article history:

Received 20 May 2014

Accepted 8 July 2014

Published 20 October 2014

\section{Keywords:}

Heterogeneous catalyst

Optimisation

Oxidation

para-Xylene

Promoter

Terephthalic acid

\begin{abstract}
A B S T R A C T
The oxidation of para-xylene to terephthalic acid has been commercialised as the AMOCO process $(\mathrm{Co} / \mathrm{Mn} / \mathrm{Br}$ ) that uses a homogeneous catalyst of cobalt and manganese together with a corrosive bromide compound as a promoter. This process is conducted in acidic medium at a high temperature $\left(175-225^{\circ} \mathrm{C}\right)$. Concerns over environmental and safety issues have driven studies to find milder oxidation reactions of para-xylene. This review discussed past and current progress in the oxidation of para-xylene process. The discussion concentrates on the approach of green chemistry including (1) using heterogeneous catalysts with promising high selectivity and mild reaction condition, (2) application of carbon dioxide as a co-oxidant, and (3) application of alternative promoters. The optimisation of para-xylene oxidation was also outlined.
\end{abstract}

(c) 2014, Dalian Institute of Chemical Physics, Chinese Academy of Sciences. Published by Elsevier B.V. All rights reserved.

\section{Introduction}

Terephthalic acid is a main component in the polyester industry, and is used in polyester terephthalate (PET) and polyester fibre manufacturing. About $70 \%$ of terephthalic acid used in PET manufacturing is produced from the oxidation process of para-xylene [1,2]. Besides its use in the manufacturing of plastic ware and drinking bottles, terephthalic acid can also be used in other applications such as in textiles, as a carrier in paints, and as a coating resin (Fig. 1).

The largest producers of terephthalic acid in commercial production are British Petroleum (BP), BP Zhuhai Chemical Company (Ltd.) and JBF Petrochemicals Ltd. (JBF), with an annual production of terephthalic acid of more than $10 \mathrm{Mt}$. All the plants are located in Europe and North America, China and India (http://www.technip.com; accessed on 25 June 2014).
The other main license holders for terephthalic acid production are DuPont, Dow Chemical, Mitsubishi Chemical, Eastman Chemical, Hitachi, Mitsui Chemicals, Interquisa, and Grupo Petromex. Currently, the market price of terephthalic acid is about 1100-1200 USD/t (bp.com/annualreport; accessed 31 Jan. 2014). It is worthwhile to mention that the largest application of PET is in textiles (Fig. 2) [3].

\subsection{Initial development of para-xylene oxidation}

The first oxidation of para-xylene was recorded in 1912 by Ciamician and Silber [4]. They studied the effect of light on the oxidation of some benzene derivatives including para-xylene. Molecular oxygen was used as the oxidant, and these derivatives were exposed to sunlight for a year. As a result, terephthalic acid was produced as one of the products besides $p$-toluic

\footnotetext{
* Corresponding author. Tel: +6-09-5492384; Fax: +6-09-5492766; E-mail: mohdhasbi@ump.edu.my This work was supported by Universiti Malaysia Pahang and the Ministry of Education, Malaysia for Exploratory Research Grant Scheme (ERGS) (RDU 120605) and again Ministry of Education, Malaysia support for MyPhD funding aid (Nor Aqilah Mohd Fadzil).
} 


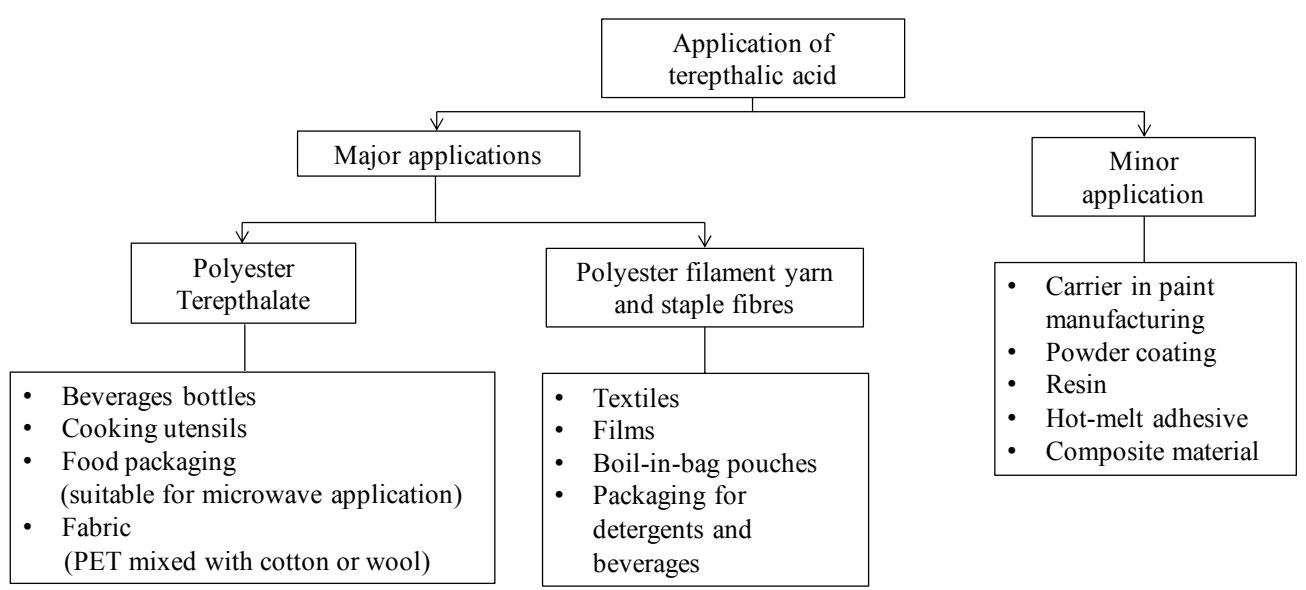

Fig. 1. Application of terephthalic acid in the polyester industry. http://www.bp.com/liveassets/bp_internet/belgium/belgium_geel/STAGING/local_assets/downloads_pdfs/G_3_08_3_06_PTA_UK.pdf (accessed on 12 February 2014); http://www.ril.com/html/business/polyester_inter_pta.html (accessed on 18 March 2014); [5] http://www.iocl.com/Products/PurifiedTerephthalicAcid.aspx (accessed on 18 March 2014); [6] http:// www.eastman.com/Products/Pages/ProductHome.aspx?Product=71001808 (accessed on 18 March 2014).

acid [5].

A decade after Ciamician and Silber's study, Stephens (1926) modified the oxidation process by changing the sunlight exposure to the use of dimmed light. The study was conducted at $100{ }^{\circ} \mathrm{C}$, and the reaction time was $24-60 \mathrm{~d}$ with the major product of xylenes and monoaldehydes. Stephens's study contributed to the study of the oxidation mechanism by revealing that the reactants (hydrocarbon and alkane) undergo stepwise oxidation and gave aldehydes and ketones as the intermediates. Besides that, Stephens also showed the inhibiting effect of water in the oxidation process [6]. However, these studies by Ciamician and Silber and Stephens were not practical for industrial application due to the long reaction time. Therefore, the use of a catalyst, either a homogeneous or heterogeneous catalyst, for the oxidation of para-xylene to terephthalic acid has received a warm welcome.

\subsection{AMOCO commercial process}

Before the AMOCO process was commercialised in the late 1970s, a few processes were used to produce high quality terephthalic acid. One of these processes was conducted with the hazardous condition of nitric acid as the oxidant at high temperature $200^{\circ} \mathrm{C}$ and $1.35 \mathrm{MPa}$ of oxygen pressure. A precipitate of terephthalic acid was formed that was separated and purified to give the high quality compound. A high quality terephthalic acid is defined as the purified product with an impurity content of 4-carboxybenzaldehyde (4-CBA) less than $25 \mathrm{ppm}$.

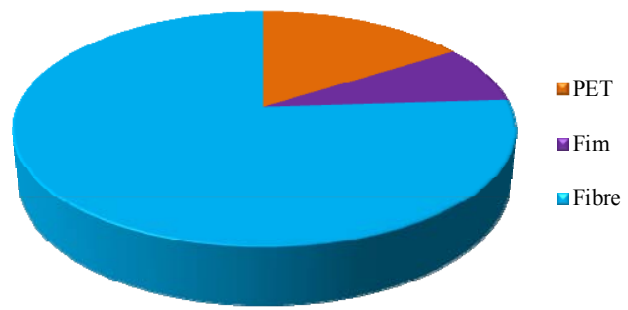

Fig. 2. Terephthalic acid consumption (2011-2012) around the world.
However, many steps are required for the purification process $[7,8]$ and the purified yield was still contaminated with coloured impurities. These impurities subsequently contributed to the deteriorated quality of the product. Therefore, esterification with methanol to dimethyl terephthalate (DMT) was introduced as an alternative route to avoid inconveniences in the purification process.

In addition, DMT was used as a replacement for terephthalic acid. In the DMT route, the oxidation of para-xylene is conducted with a cobalt catalyst in the absence of a solvent, and the temperature and pressure are $180{ }^{\circ} \mathrm{C}$ and $0.8 \mathrm{MPa}$ of air, respectively. The $p$-toluic acid produced is esterified with methanol to methyl $p$-toluate followed by autoxidation to monomethyl terephthalate. Monomethyl terephthalate is then esterified by methanol again to form DMT. The complete steps of the esterification of $p$-toluic acid to DMT is shown in Scheme $1[9]$.

PET was patented by John Rex Whinfield in 1946 [10]. As $p$-toluic acid is resistant to oxidation by the cobalt catalyst, the process relies on the oxidation of methyl $p$-toluate (produced as a result of esterification by methanol) to monomethyl terephthalate [7]. This situation constrained the production of terephthalic acid as it increased the operation cost due to the many steps required in the esterification by methanol.

The solution to the resistance of $p$-toluic acid to oxidation was solved by the discovery of bromide-controlled air oxidation in 1955. This discovery led to the implementation of the

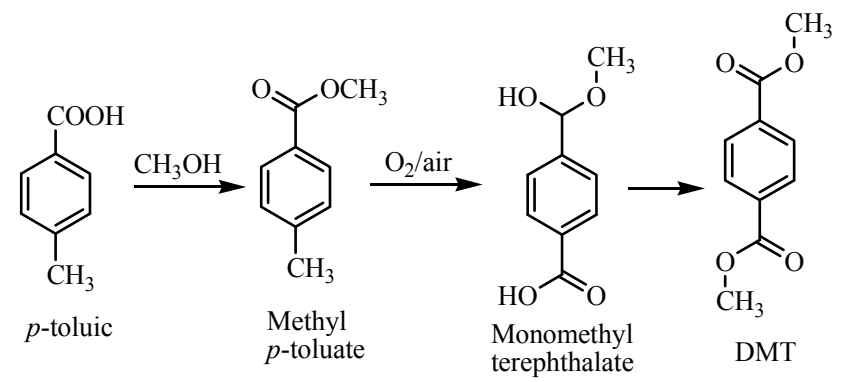

Scheme 1. Esterification of $p$-toluic acid to DMT [9]. 


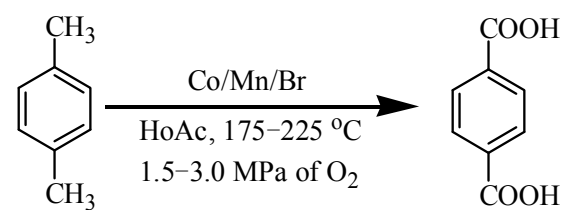

Scheme 2. AMOCO commercial process for para-xylene oxidation to terephthalic acid [15].

AMOCO process [11-13]. In the AMOCO process, the oxidation of para-xylene is conducted using a combination of three ions as homogeneous catalyst, which are cobalt, manganese and bromide ions. Acetic acid and oxygen/air are used as solvent and oxidant, respectively [14]. The common sources of bromide ion are hydrobromic acid ( $\mathrm{HBr}$ ) and sodium bromide ( $\mathrm{NaBr}$ ). The oxidation operates at $175-225^{\circ} \mathrm{C}$ and $1.5-3.0 \mathrm{MPa}$ of oxygen. Terephthalic acid is formed mostly in the form of a solid due to the low solubility of terephthalic acid in acetic acid. The AMOCO process is promising as more than $98 \%$ of the $p a-$ $r a$-xylene reacts, while the terephthalic acid selectivity yield is about $95 \%$ in a reaction time of 8-24 h (Scheme 2).

As shown in Scheme 3, the consecutive oxidation of the methyl group takes place for $p$-toluic acid and 4-CBA. In order to get terephthalic acid as the product, purification from impurities including the 4-CBA content in crude terephthalic acid must be conducted. In the purification process, the crude terephthalic acid (a solid terephthalic acid that has undergone centrifugation and drying) is dissolved in hot water to reduce 4-CBA to $p$-toluic acid. This reduction process is by catalytic hydrogenation with a palladium catalyst. Then, purified terephthalic acid is obtained. Apart from the AMOCO process, other catalytic processes to produce terephthalic acid by direct oxidation have been widely studied to find the best process for terephthalic acid production for industrial purposes.

\section{Catalytic oxidation of para-xylene}

\subsection{Homogeneous catalytic oxidation of para-xylene}

As mentioned earlier, the AMOCO process is a homogeneous

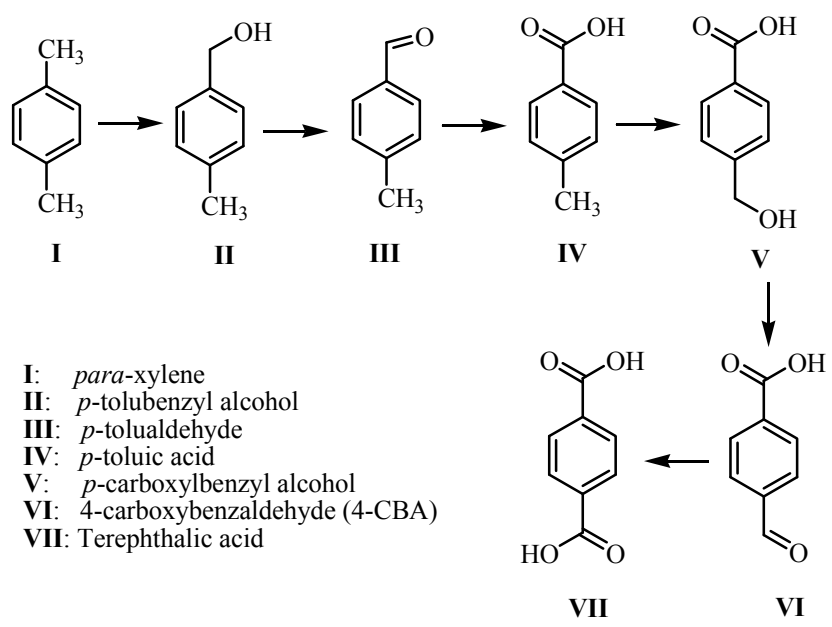

Scheme 3. Oxidation products of the para-xylene oxidation process [1]. liquid phase oxidation. Even though the production yield of this process is promising, the utilisation of hydrobromic acid ( $\mathrm{HBr}$ ) or sodium bromide ( $\mathrm{NaBr}$ ) as the bromide ion source leads to a hazardous reaction condition in terephthalic acid production due to the corrosive nature of $\mathrm{HBr}$. Besides that, the bromide sources are also not environmentally friendly as they are harmful and dangerous to handle [16].

Therefore, efforts to apply a homogeneous catalyst with the utilisation of a bromide ion of a less corrosive nature have been conducted. For example, Ref. [16] used $\mathrm{CoBr}_{2}$ and $\mathrm{MnBr}_{2}$ catalysts as free radical sources. Using these catalysts, a high yield of terephthalic acid was achieved (93\%) at $100{ }^{\circ} \mathrm{C}$ with a $\mathrm{Br} / \mathrm{Co}$ atomic ratio of three. However, the utilisation of this less corrosive bromide ion still needs an expensive titanium reactor to avoid corrosion in the reactor. Thus, this disadvantage makes the oxidation process less interesting [5,17]. In para-xylene oxidation that uses a bromide ion, the oxidation temperature should be lower than the commercial one $\left(175-225^{\circ} \mathrm{C}\right)(1)$ to make the reaction process less hazardous, (2) to lower the corrosion rate of the reactor, and (3) to hinder the negative effect of the corrosive bromide ion at high temperature.

\subsubsection{Trends in the homogeneous catalytic oxidation of para-xylene}

There are two major trends in the research on the homogeneous catalytic oxidation of terephthalic acid production: (1) oxidation in sub- and supercritical water, and (2) heterogenisation of the homogeneous catalyst. The oxidation of para-xylene in sub- and supercritical water is due to the desire to apply an environmentally friendly solvent. In this method, water is used as a solvent to replace the non-environmentally friendly solvents such as acetic acid, acetonitrile, and dimethylformamide (DMF) [18,19].

However, a high temperature is required due to the limitations of water as a solvent in the production of terephthalic acid. A poor solvent will lead to less solubility of para-xylene, and that will lead to a low yield of terephthalic acid. Therefore, in the sub- and supercritical water method, a high temperature $\left(>300^{\circ} \mathrm{C}\right)$ has to be used to ensure a high solubility of $p a-$ $r a$-xylene for the production of the desired terephthalic acid. Once the temperature rises to a critical temperature, the physical properties of water will resemble the physical properties of an organic solvent [20].

In addition, as the water temperature keeps increasing from 300 to $800{ }^{\circ} \mathrm{C}$, the properties of water such as the dielectric constant and terephthalic acid solubility in water $(\mathrm{g} / 100 \mathrm{~g}$ water) show positive effects. A study on the supercritical fluid behaviour revealed that the dielectric constant decreased as the temperature increased [21]. This was due to the disruption of hydrogen bonds once the temperature increased to $27{ }^{\circ} \mathrm{C}$ and higher.

Meanwhile, the solubility of terephthalic acid in water increases linearly with temperature. Therefore, it can be concluded that the reaction and yield of the reaction can be adjusted by modifying the reaction temperature. As shown in Table 1, the application of sub- and supercritical water can give a high yield in terephthalic acid ( $>50 \%)$. However, for industri- 
Table 1

Production of terephthalic acid in the homogeneous catalytic oxidation of para-xylene using sub- and supercritical water.

\begin{tabular}{lccc}
\hline $\begin{array}{l}\text { Reaction conditions } \\
\text { (temperature/oxidant) }\end{array}$ & Catalyst & $\begin{array}{c}\text { Yield of terephthalic } \\
\text { acid }^{\mathrm{a}}(\%)\end{array}$ & Ref. \\
\hline $300^{\circ} \mathrm{C} / \mathrm{H}_{2} \mathrm{O}_{2} \mathrm{~b}$ & $\mathrm{MnBr}_{2}$ & 50 & {$[22]$} \\
$300^{\circ} \mathrm{C} / \mathrm{O}_{2} \mathrm{~b}$ & $\mathrm{MnBr} 2$ & 80 & {$[23]$} \\
$380^{\circ} \mathrm{C} / \mathrm{H}_{2} \mathrm{O}_{2} \mathrm{c}$ & $\mathrm{MnBr}_{2}$ & 95 & {$[24,25]$} \\
$380^{\circ} \mathrm{C} / \mathrm{O}_{2} \mathrm{c}$ & $\mathrm{CuBr} 2$ & 56 & {$[26]$} \\
$380^{\circ} \mathrm{C} / \mathrm{O}_{2} \mathrm{c}$ & $\mathrm{NiBr}_{2}$ & 59 & {$[26]$} \\
$380^{\circ} \mathrm{C} / \mathrm{O}_{2} \mathrm{c}$ & $\mathrm{Cu} / \mathrm{Co} / \mathrm{NH}_{4} / \mathrm{Br}$ & 71 & {$[26]$} \\
$380^{\circ} \mathrm{C} / \mathrm{O}_{2} \mathrm{c}$ & $\mathrm{Cu} / \mathrm{Co} / \mathrm{Br}$ & 60 & {$[26]$} \\
$400^{\circ} \mathrm{C} / \mathrm{H}_{2} \mathrm{O}_{2} \mathrm{c}$ & $\mathrm{MnBr}$ & 90 & {$[27]$} \\
\hline
\end{tabular}

a Calculated yield of terephthalic acid $=$ conversion (\%) $\times$ selectivity $(\%) ;{ }^{b}$ Subcritical water (temperature $=100-374{ }^{\circ} \mathrm{C}$ ); ${ }^{\mathrm{c}}$ Supercritical water (temperature $>374{ }^{\circ} \mathrm{C}$ )

al application, the energy, nature of chemical, and operation costs are high. Even though sub- and supercritical water can produce a large amount of terephthalic acid, the temperature and pressure applied in this method are far from safe for commercial practice.

The second method in the homogeneous catalytic oxidation of para-xylene is the heterogenisation of the homogeneous catalyst. Due to the good ability of homogeneous catalyst in the production of terephthalic acid, this catalyst is normally desired. The limitations in the homogeneous catalyst are (1) metal precipitation that prevents the effective performance of the catalyst, (2) a separation process is required after the process has completed, and (3) restricted reusable catalyst application. The ultimate objective of the heterogenisation of homogeneous catalyst is to suppress the limitations in the homogeneous catalyst. Ref. [14] used bentonite as a medium to heterogenise the homogeneous catalyst of cobalt and manganese. With this step, the catalyst can be reused. Other researchers have also reported attempts to heterogenise the homogeneous catalyst by encapsulating active metal complexes and Co/Mn in zeolites [28-30]. These attempts have drawn the attention of researchers on the application of a heterogeneous catalyst.

\subsubsection{Reaction mechanism for the homogeneous catalytic oxidation system of para-xylene}

The homogeneous catalytic mechanism of para-xylene to terephthalic acid is based on free radical generation [31-37]. The most common catalyst in the homogeneous catalytic system of para-xylene to terephthalic acid is cobalt, manganese, or bromine. Bromine from $\mathrm{HBr}$ is used as a promoter and acetic acid is used as a solvent. This catalyst plays its role by generating a radical species (denoted as *) through an electron transfer process shown in Eq. (1). In addition, the presence of $\mathrm{HBr}$ and acetic acid enhances and accelerates radical species generation by the reaction of the Brönsted acid of acetic acid that donates protons to water and hence produces acetate anions. The acetate anion reacts with $\mathrm{HBr}$ and generates bromine radical, as shown in Eqs. (2) and (3) [38].

Thus, bromine radicals promote the reaction by abstracting the hydrogen atom from the methyl group thus resulting in the second radical of the substrate. The subsequent oxidation then takes place in the presence of $\mathrm{O}_{2}$ as an oxidant (see Eqs. (4) to (9)). It is worthwhile to mention that the cobalt catalyst induces the abstraction of the hydrogen atom at the beginning of the reaction. Then, the participation of the manganese catalyst is to cause the further oxidation to aldehyde as shown in Eq. (5). This is due to the inability on the cobalt catalyst to oxidise further. Thus, the synergistic effect of both cobalt and manganese is important to oxidise para-xylene to terephthalic acid. As mentioned, the role of bromine is as a promoter to generate radical compound species [38].
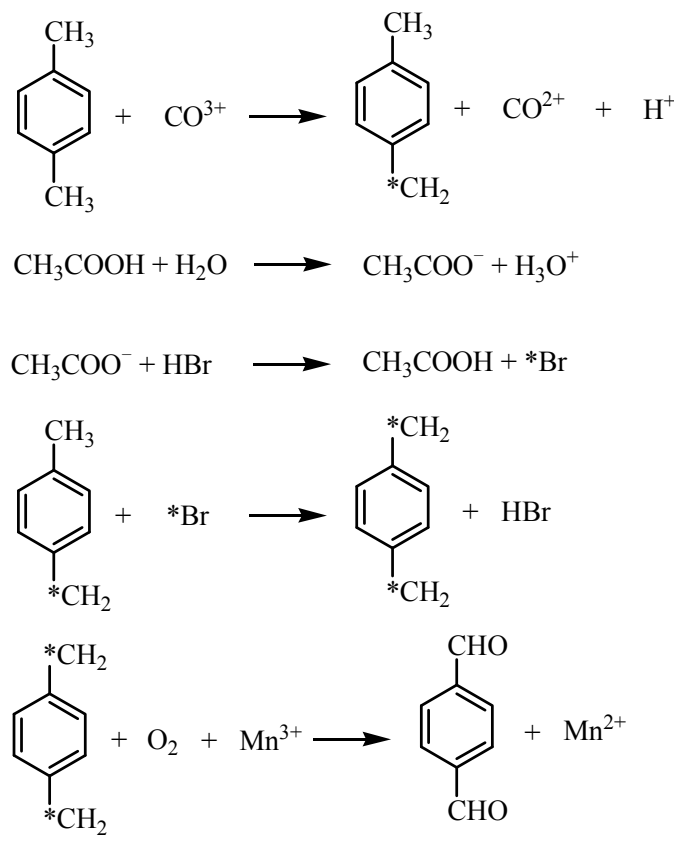<smiles>O=Cc1ccc(C=O)cc1</smiles><smiles>O=Cc1ccc(C=O)cc1</smiles>

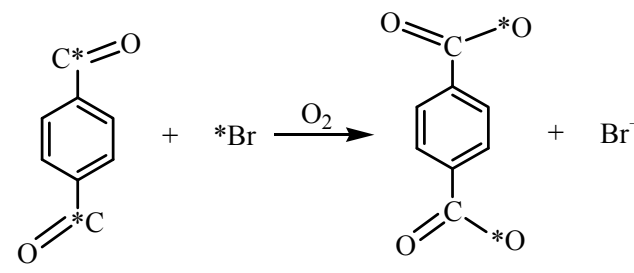<smiles>O=C(O)c1ccc(C(=O)O)cc1</smiles> 


\subsection{Heterogeneous catalytic oxidation of para-xylene}

Up to a few decades ago, according to Hronec and Hrabě (1986), the use of a heterogeneous catalyst in a hydrocarbon liquid phase was not as effective as using a homogeneous catalyst [39]. This low activity included para-xylene oxidation in the liquid phase medium. Co-Y and Mn-Y zeolites were used for para-xylene oxidation, but the terephthalic acid yielded was low, and the terephthalic acid selectivity yield was less than $15 \%$ [40].

However, recently, numerous investigations were conducted for a heterogeneous catalyst in the liquid phase oxidation of para-xylene. An impressive performance in heterogeneous catalytic oxidation of para-xylene was recorded in 2001 by Chavan's group who employed a heterogeneous catalyst using neat and $\mu_{3}$-oxo bridged $\mathrm{Co} / \mathrm{Mn}$ cluster complexes encapsulated in zeolite $\mathrm{Y}$ as a catalyst and acetic acid-water as a solvent under $200{ }^{\circ} \mathrm{C}$ and $6.1 \mathrm{MPa}$ of air pressure; $100 \%$ conversion of para-xylene with $98.9 \%$ terephthalic acid production was recorded in $2 \mathrm{~h}$ reaction time [28]. However, the high terephthalic acid production achieved was accompanied by two problems namely (1) the yield was produced at a higher pressure than the pressure used in the commercial process and (2) the environmental issue related to the application of acetic acid as a solvent in the reaction.

However, this high activity proved that a heterogeneous catalyst can also produce a high yield of terephthalic acid. In addition, the application of a heterogeneous catalyst is better than a homogeneous catalyst because the heterogeneous catalyst (1) is easy to separate from the target product, (2) can be recycled, and (3) mostly does not need the presence of a bromide ion or corrosive chemical as a promoter. There are many heterogeneous catalysts that have been patented and claimed to give a high conversion and selectivity for para-xylene and terephthalic acid production, respectively. These catalysts consist of palladium, antimony and molybdenum supported on the $\mathrm{TiO}_{2}$. These catalysts can also be combined with metal acetate. However, the recyclability of the catalyst is still a concern in this patent [41].

For the record, previously, the authors reported works on the activation of the primary $\mathrm{C}-\mathrm{H}$ bond of xylenes and its derivatives using a supported metal heterogeneous catalyst. The works included attempts of AuPd alloy nanoparticle catalyst application with molecular oxygen $\left.\mathrm{CO}_{2}\right)$ as an oxidant to activate the primary $\mathrm{C}-\mathrm{H}$ bond of xylenes (ortho-, meta-, para-) into oxygenates such as $n$-toluyl alcohol, $n$-tolualdehyde, and $n$-toluic acid [42-44]. The works confirmed that a AuPd alloy nanoparticle catalyst can oxidise the primary $\mathrm{C}-\mathrm{H}$ bond of $p a-$ $r a$-xylene and xylene derivatives with a turnover number (TON) of 171 and 581, respectively, under mild reaction conditions, namely, $160^{\circ} \mathrm{C}$ and $1.0 \mathrm{MPa}$ of oxygen [42].

Moreover, works on the same catalyst but at a lower reaction temperature for methane oxidation, with methanol selectivity of $89.2 \%$ achieved at $50{ }^{\circ} \mathrm{C}$ and with in situ $\mathrm{H}_{2} \mathrm{O}_{2}$ as an oxidant, has also been conducted $[43,44]$. The authors also studied the oxidation of toluene as another model for primary $\mathrm{C}-\mathrm{H}$ bond activation. In addition, the oxidation of toluene was conducted in a solvent-free condition with benzyl benzoate selectivity of $85.5 \%, 94.4 \%$ conversion, and TON of 1534 . This method applied the mild reaction condition as stated earlier [42]. Thus, a similar method can be utilised for activating the primary $\mathrm{C}-\mathrm{H}$ bond of para-xylene with terephthalic acid as the target product.

On the other hand, the effort to investigate a heterogeneous catalyst in para-xylene oxidation should not only focus on the high yield of terephthalic acid and selectivity, but also on the implementation of a safe and green chemical process such as a nonhazardous solvent and mild operation condition. For example, Ref. [45] found a novel heterogenous catalyst for $p a$ $r a$-xylene oxidation, namely, nanoparticles of $\mathrm{CeO}_{2}$; almost $40 \%$ terephthalic acid was produced. The reaction was conducted under mild conditions, namely, $70{ }^{\circ} \mathrm{C}, 0.1 \mathrm{MPa}$ of oxygen pressure, and water as the solvent, making this study interesting for further investigation. However, the application of a heterogeneous catalyst for selective para-xylene oxidation has only been done in a limited number of studies $[28,45,46]$. Table 2 summarises the application of a heterogeneous catalyst in $p a-$ ra-xylene oxidation.

It is worthwhile to mention that the mechanisms for the homogeneous and heterogeneous catalytic systems for pa$r a$-xylene oxidation to terephthalic acid differ. The oxidation pathways of the homogeneous catalytic system are influenced by the radicals species produced resulting in $\mathrm{C}-\mathrm{H}$ bond activation. The mechanism of the heterogeneous catalytic system for para-xylene oxidation to terephthalic acid does not rely on the generation of a radical compound, but it relies on the surface reaction of the catalyst. By referring to the reaction mechanism of the heterogeneous catalytic system involving toluene as starting material and molecular oxygen $\left(\mathrm{O}_{2}\right)$ as an oxidant $[38,48]$, the possible mechanism of para-xylene oxidation is illustrated in Eqs. (10) to (15).

On the other hand, $\mathrm{C}-\mathrm{H}$ bond activation can occur either by homolytic or heterolytic dissociation. Homolytic dissociation is caused by an electrophile oxygen species, while heterolytic dissociation is caused by a nucleophile oxygen species (saturated $\mathrm{O}_{2}$ ). An example of a nucleophile oxygen species is a terminal oxygen group [48]. In detail, in the heterogeneous catalytic system, the activation of the $\mathrm{C}-\mathrm{H}$ bond typically is achieved

Table 2

Comparison of heterogeneous catalysts for para-xylene oxidation.

\begin{tabular}{|c|c|c|c|c|c|}
\hline Catalyst & Oxidant & $\begin{array}{c}\text { Reaction } \\
\text { conditions }\end{array}$ & $\begin{array}{l}\text { Yield } \\
(\%)\end{array}$ & TOF & Ref. \\
\hline$\overline{\mathrm{CeO}_{2}}$ & $\mathrm{O}_{2}$ & $\begin{array}{l}\text { Solvent: Water } \\
70^{\circ} \mathrm{C}, 0.1 \mathrm{MPa}\end{array}$ & 40.0 & 8.5 & [45] \\
\hline $\begin{array}{l}\mu_{3}-\mathrm{Oxo}-\mathrm{Bridged} \\
\mathrm{Co} / \mathrm{Mn}-\mathrm{Y}\end{array}$ & Air & $\begin{array}{l}\text { Solvent: Acetic acid } \\
20{ }^{\circ} \mathrm{C}, 3.8 \mathrm{MPa}\end{array}$ & 98.9 & 203 & [28] \\
\hline $\mathrm{Cu} / \mathrm{Mn}-\mathrm{NaX}$ & Air & $\begin{array}{l}\text { Solvent: Acetic acid } \\
30^{\circ} \mathrm{C}, 3.3 \mathrm{MPa}\end{array}$ & 5.0 & 186.7 & [40] \\
\hline $\mathrm{Pd} / \mathrm{Sb} / \mathrm{Mo}-\mathrm{TiO}_{2}$ & $\mathrm{O}_{2}$ & $\begin{array}{l}\text { Solvent: Water } \\
210^{\circ} \mathrm{C}, 3.1 \mathrm{MPa}\end{array}$ & 90.85 & 23.2 & [41] \\
\hline AuPd/MIL-101 & $\mathrm{O}_{2}$ & $\begin{array}{l}\text { Solvent-less } \\
120^{\circ} \mathrm{C}, 1 \mathrm{MPa}\end{array}$ & 40.2 & 25.13 & [51] \\
\hline $\mathrm{AuPd} / \mathrm{C}$ & $\mathrm{O}_{2}$ & $\begin{array}{c}\text { Solvent-less } \\
160^{\circ} \mathrm{C}, 1.0 \mathrm{MPa}\end{array}$ & 74.5 & 7.1 & [47] \\
\hline
\end{tabular}




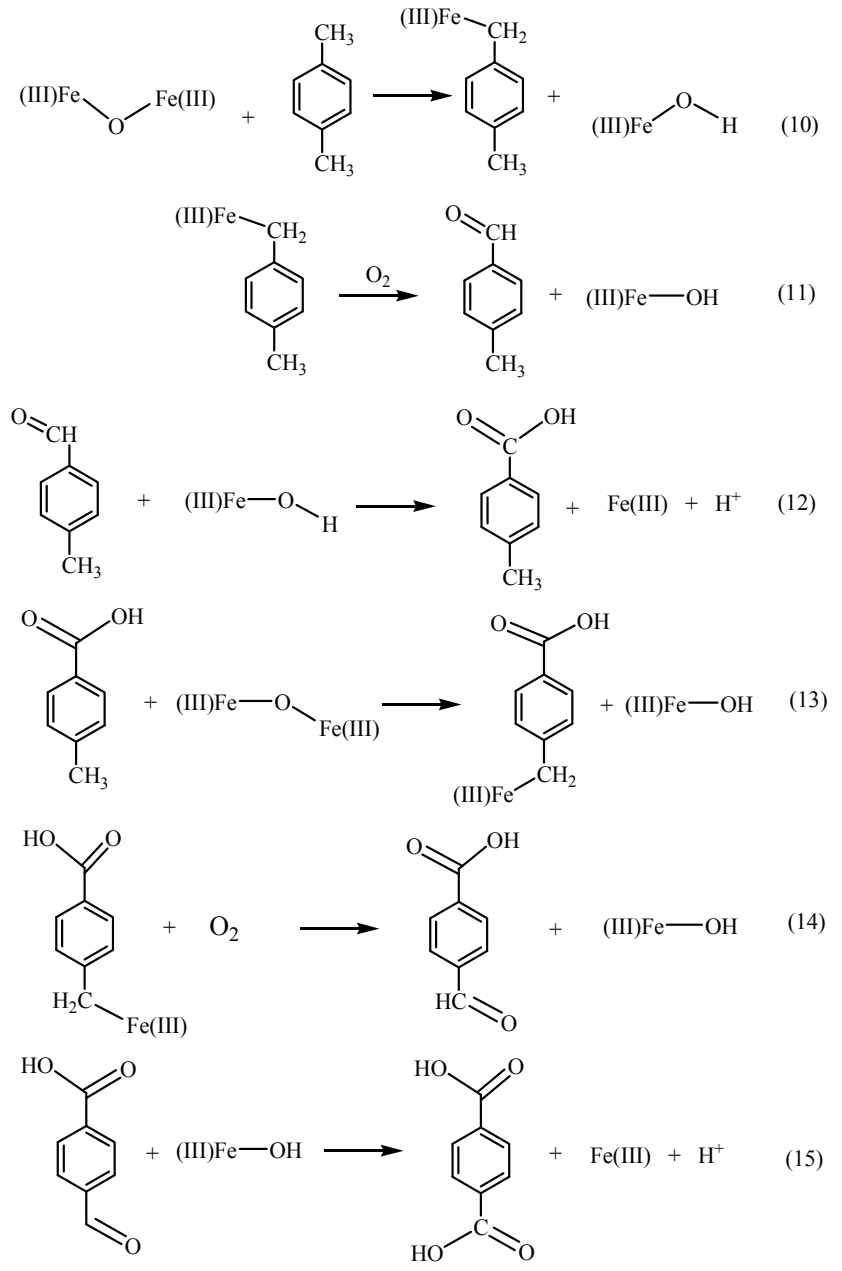

when the catalyst (Fe-ZSM-5) activates the $\mathrm{C}-\mathrm{H}$ bond after the terminal oxygen of Fe(III)-O-Fe(III) has abstracted the hydrogen atom from para-xylene as shown in Eq. (10) [48-50]. Then, the subsequent oxidation reactions take place (Eqs. (11)-(15)). No additive is added in the heterogeneous catalytic system and this makes it a convenient reaction [51]. However, in the discussion on this pathway, there are some disagreements among researchers. Therefore, an extensive study on the heterogeneous catalytic system of para-xylene oxidation to terephthalic acid is highly recommended.

\section{Selectivity in catalytic oxidation of para-xylene}

In general, the selectivity in the reaction of para-xylene oxidation can be defined as the selectivity to the desired product of terephthalic acid. The similar structure of terephthalic acid and 4-CBA gives a problem in the purification of terephthalic acid. Besides, 4-CBA is co-crystallised with terephthalic acid. Therefore, in normal polyester terephthalate manufacturing, the 4-CBA content in terephthalic acid must be less than 25 ppm, as previously mentioned [52]. Otherwise, the quality of the polyester terephthalate is questionable.

The difficult problems in getting good selectivity in $p a-$ $r a$-xylene oxidation are (1) in controlling the production of other products besides terephthalic acid and (2) in controlling the undesired over-oxidation of para-xylene to carbon dioxide.
The dilemma in controlling each situation individually is that they are related to each other. When 4-CBA production is decreased, the tendency to form carbon dioxide increased $[53,54]$.

In order to get good selectivity, the proportion of the catalyst should be right. For common homogeneous catalysts in the oxidation of para-xylene, namely, bromine, cobalt, and manganese, when the ratio of bromine/metal decreased, there is a decrease in 4-CBA production. This is due to the smaller proportion of bromine in the catalyst, thus the activity of the catalyst is reduced. In addition, if the metal content is higher than the bromine content in the ratio of bromine/metal, then the catalyst is not able to give a good performance. This is due to the hindrance of the catalytic activity for peroxide decomposition [55].Therefore, the best solution is to increase the cobalt and manganese ratio with the relative increase of bromine, thus the activity of catalyst will be higher. The higher activity of the catalyst reflects the catalyst capability to catalyse the decomposition of peroxide. As a result, the generation of free radicals can be increased. However, this situation should be controlled well; otherwise, over-oxidation will occur and this is not favourable.

On the other hand, for a heterogeneous catalyst, the selectivity is the main issue, particularly for para-xylene oxidation process as the selectivity for its desired product is relatively low compared to a homogeneous catalyst and enzyme catalyst $[28,45,57,58]$. Specifically, an enzyme catalyst has the ability to control selectivity due to the location of the active site of the enzyme in the binding pocket. The active site allows the noncovalent interaction between the binding pocket and reactant. As a result, the reactant binds neatly with the active site in a specific orientation. For example, the partial oxidation of pa$r a$-xylene between bacteria such as those from the genus Burkholderia and Nocardia and enzyme has been reported $[57,58]$.

Thus, an attempt to control the selectivity of heterogeneous catalyst by changing and controlling the noncovalent interaction in the heterogeneous catalyst has been conducted. Thiolate self-assembled monolayer (SAMs) was deposited on $\mathrm{Pd} / \mathrm{Al}_{2} \mathrm{O}_{3}$ to alter the orientation of the reactant on the active site. The altered binding improved the noncovalent interaction between reactant and active site. Specifically, the noncovalent interaction was improved by changing the thiolate hydrocarbon tail [56].

In addition, the characteristics of the heterogeneous catalyst used also highly influence the selectivity in para-xylene oxidation. As reported by Chavan and his colleagues, terephthalic acid selectivity is higher for a $\mathrm{CoMn}_{2}$ neat cluster encapsulated in zeolite Y than Co and Mn encapsulated zeolite Y. This is due to the strong heteronuclear cluster of $\mathrm{CoMn}_{2}$. In addition, the active heteronuclear cluster of $\mathrm{CoMn}_{2}$ suppresses the performance of $\mathrm{Co}$ and $\mathrm{Mn}$ alone, with terephthalic acid selective yield of $92.8 \%, 15.2 \%$ and $10.4 \%$, respectively [40]. Moreover, the geometric distortion of materials encapsulated in a zeolite can affect the selectivity due to the changes in the electron density of the metal ion site. As a result, the behaviour of the oxidation-reduction reactions for that particular material changes [59]. 
Other attempts to improve the selectivity of the heterogeneous catalyst are by altering the size and shape of the catalyst and by deactivating the catalyst surface [60-62]. Generally, the selectivity to the desired product can be controlled by changing reaction conditions such as operating temperature, pressure, mild or strong oxidants, co-oxidant, and reaction time. All these reaction conditions can affect the selectivity. The selectivity to a desired product for a heterogeneous catalyst can be achieved by deactivating certain locations in the active site. This deactivation can be done by poisoning, leaching, fouling, and sintering [63].

\section{Carbon dioxide as co-oxidant}

$\mathrm{CO}_{2}$ can also facilitate the catalytic oxidation of para-xylene. $\mathrm{CO}_{2}$ can be fed in with both homogeneous and heterogeneous catalysts. The introduction of $\mathrm{CO}_{2}$ into the reaction is relevant as sometimes the effort to maximise terephthalic acid production requires the utilisation of a flammable solvent and a high concentration of an explosive oxidant such as $\mathrm{H}_{2} \mathrm{O}_{2}$ and $\mathrm{O}_{2}$. Thus, the addition of $\mathrm{CO}_{2}$ can suppress the probability of explosion and fire during the reaction when high temperature and $\mathrm{O}_{2}$ concentration are used. This safety aspect is an advantage of using $\mathrm{CO}_{2}$ in the catalytic oxidation of para-xylene.

Besides that, $\mathrm{CO}_{2}$ also enhances the oxidation activity. Yoo J. $\mathrm{S}$. and his research team studied the effect of $\mathrm{CO}_{2}$ on the liquid phase oxidation of para-xylene and found that the addition of $\mathrm{CO}_{2}$ helps consume $\mathrm{O}_{2}$ [64]. The enhanced solubility of $\mathrm{O}_{2}$ could be due to the positive effect of the solvent expansion nature of $\mathrm{CO}_{2}$ as a co-oxidant [64]. In addition, the presence of $\mathrm{CO}_{2}$ can decrease the impurities in the terephthalic acid produced. This can be done by increasing the $\mathrm{CO}_{2}$ pressure and decreasing the $\mathrm{O}_{2}$ pressure. This makes the purification of crude terephthalic acid less complicated.

Moreover, $\mathrm{CO}_{2}$ can be used to avoid over-oxidation of $p a-$ $r a$-xylene [65-68]. The reactivity of $\mathrm{CO}_{2}$ is low compared to oxygen and water, thus making $\mathrm{CO}_{2}$ a soft oxidant for either the single or co-oxidant process. This nature makes the over-oxidation process improbable, as mentioned before, as the addition of $\mathrm{CO}_{2}$ molecules leads to the deactivation or poisoning of the active site, thus further oxidation has to occur at a nondeactivated active site.

However, the application of $\mathrm{CO}_{2}$ as a sole or co-oxidant in para-xylene oxidation to terephthalic acid has not been extensively studied. This could be due to that attention is given more to the enhancement of terephthalic acid yield than to the application of $\mathrm{CO}_{2}$ in the reaction as $\mathrm{CO}_{2}$ is well known as a weak oxidant. In para-xylene oxidation to terephthalic acid, $\mathrm{CO}_{2}$ is believed to be involved in the activation of para-xylene or substrate when the operating temperature is less than $400^{\circ} \mathrm{C}$. This is because, near $400{ }^{\circ} \mathrm{C}$, thermal cracking of the substrate can take place, and thus the role of $\mathrm{CO}_{2}$ to activate the substrate is then doubtful [69]. Then, further oxidation will take place, as shown in Eqs. (16-17) and Scheme 3 [1]. Moreover, near 400 ${ }^{\circ} \mathrm{C}$, thermal cracking activates the $\mathrm{C}-\mathrm{H}$ bond of the substrate, and this activation results in radical species (denoted as *), followed by the subsequent oxidation in the presence of $\mathrm{O}_{2}$, as shown in Eqs. (16) and (17).

However, when the operation temperature is less than 400 ${ }^{\circ} \mathrm{C}$, the effect of $\mathrm{CO}_{2}$ is significant since it causes $\mathrm{C}-\mathrm{H}$ bond activation of the para-xylene. $\mathrm{CO}_{2}$ is known as a diluent oxidant and can prevent over-oxidation to unwanted products. The way $\mathrm{CO}_{2}$ inhibits over-oxidation can be explained as follows. As the $\mathrm{C}-\mathrm{H}$ bond activation is known as a rate determining step, it can be said that the soft oxidant of $\mathrm{CO}_{2}$ leads to a slow rate determining step thus making the process occur at a slow rate. Next, the activation of $\mathrm{C}-\mathrm{H}$ bond follows the Mars-Van Krevelen mechanism. The lattice oxygen of the catalyst is responsible for activating the $\mathrm{C}-\mathrm{H}$ bond of the para-xylene $[70,71]$. This means that $\mathrm{CO}_{2}$ does not play a role in the activation of the $\mathrm{C}-\mathrm{H}$ bond. The role of $\mathrm{CO}_{2}$ only begins once $\mathrm{CO}_{2}$ reoxidises the lower valence metal oxide catalyst, as shown in Eqs. (18) and (19) [69].

As shown in Eq. (19), the reoxidation of the lower valence metal oxide leads to the formation of $\mathrm{CO}$ species. The CO formed then blocks the active sites on the catalyst surface. As a result, the catalyst activity decreases, and this is called poisoning of the active sites [72]. Once the active sites have been poisoned by $\mathrm{CO}$, the oxidation product can be controlled by blocking the active sites, which otherwise may cause over-oxidation of wanted products. In fact, as shown in a study, the poisoning can also enhance the selectivity of the target product [73].

Some researchers suggested that the role of $\mathrm{CO}_{2}$ as an oxidant is to abstract the hydrogen atom from the substrate. If this is the case, it means that $\mathrm{CO}_{2}$ is involved in the rate determining step as $\mathrm{CO}_{2}$ can activate the $\mathrm{C}-\mathrm{H}$ bond of the substrate. However, the abstraction of a hydrogen atom from the substrate is highly influenced by the acid-base properties of the catalyst. Only the basic site of the catalyst leads to hydrogen abstraction and results in radical compound formation, as shown in Eq. (20). This compound will then be oxidised further in the presence of $\mathrm{O}_{2}$ at the target product. The presence of $\mathrm{O}_{2}$ is due to the $\mathrm{CO}_{2}$ that typically only acts as a co-oxidant $[74,75]$.

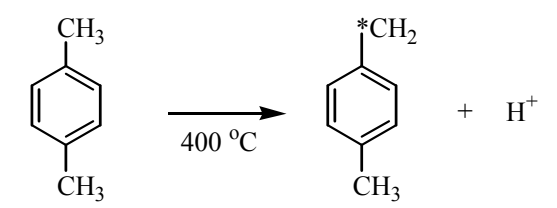<smiles>CCc1ccc(C)cc1</smiles>
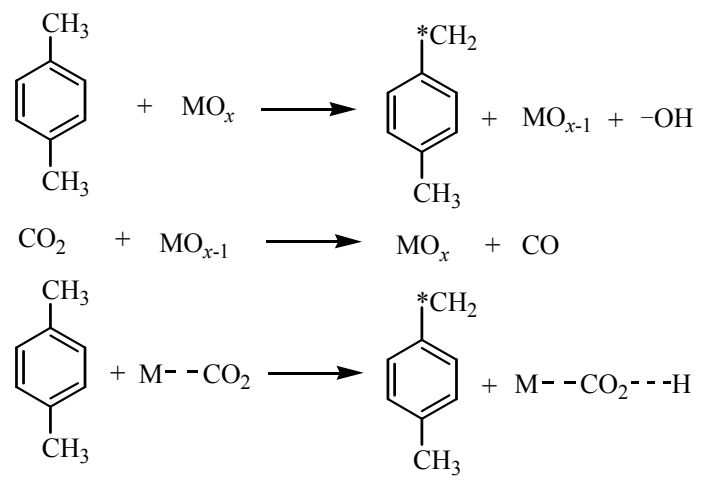
<smiles>O=C1c2ccccc2C(=O)N1O</smiles>

Scheme 4. The N-hydroxyimide (NHPI) structure.

\section{Alternative promoters in catalytic oxidation of para-xylene}

Due to the concern over the corrosive promoter such as $\mathrm{HBr}$ and $\mathrm{NaBr}$, other alternatives are demanded. $\mathrm{N}$-Hydroxyimides (NHPI) (see Scheme 4) is an organic promoter that has been used in terephthalic acid production [76]. This organic promoter was the earlier alternative for the corrosive bromide promoters as this promoter was introduced in the same decade with the AMOCO commercialisation process.

The main function of NHPI is to generate peroxy radicals for further oxidation in para-xylene. The application of NHPI as a promoter successfully produces terephthalic acid at $84 \%$ selectivity yield [77]. In addition, NHPI also catalyses the oxidation of para-xylene even at mild reaction conditions $\left(100^{\circ} \mathrm{C}\right.$ and 0.1 $\mathrm{MPa}$ of $\mathrm{O}_{2}$ ) [78]. Thus, NHPI as an alternative promoter can give good performance even in the common reaction conditions in which acetic acid is the solvent while cobalt and manganese are used as catalysts.

The mechanism of NHPI in para-xylene oxidation starts with the generation of phthalimide N-oxyl (PINO) radical. PINO radical is generated once the hydrogen atom is abstracted from NHPI. The generated PINO radical then abstracts hydrogen atom from para-xylene to form an alkyl radical. The alkyl radical reacts with dioxygen to produce a peroxy radical before the alkyl peroxide species is generated. Next, the alkyl peroxide species is decomposed to form the oxygenated product. However, NHPI needs to be added continuously to maintain the oxidation rate of para-xylene. This is because both NHPI and PINO are decomposed and this decomposition decreases the oxidation rate of the substrate $[79,80]$.

The other alternative promoter is guanidine (see Scheme 5). In 2006, Cheng and his research team examined the role of guanidine in a $\mathrm{Co} / \mathrm{Mn} / \mathrm{Br}$ catalyst for the oxidation of $p a-$ $r a$-xylene. The study showed that guanidine has a positive effect on the selectivity of the desired product. This effect was observed from the decrease of carbon oxides [81]. On the other hand, the effort to replace the corrosive $\mathrm{HBr}$ promoter with other promoter also led to the attempt to use less corrosive bromide-containing compounds such as $\mathrm{CoBr}_{2}$ and $\mathrm{MnBr}_{2}$. This attempt successfully produces $93.5 \%$ terephthalic acid yield at the $\mathrm{Br} / \mathrm{Co}$ atomic ratio of three [16].

However, there are not many studies on the application of the promoter in the heterogeneous catalytic system for $p a-$ $r a$-xylene oxidation. Cao's group reported a similar perfor-<smiles>N=C(N)N</smiles>

Scheme 5. Guanidine structure. mance to an AMOCO commercial process. However, the corrosive $\mathrm{HBr}$ was replaced with an ionic liquid promoter, which was 1-ethyl-3-methylimidazolium bromide with acetic acid as the solvent. The catalyst used is based on SABIC patents that used a metal catalyst such as chromium or cobalt metal catalyst. The reaction conditions are $215^{\circ} \mathrm{C}$ and $1.8 \mathrm{MPa}$ of molecular oxygen [82].

\section{Current process: Obstacles and challenges}

The commercial AMOCO process is dominant in the oxidation of para-xylene to terephthalic acid, and most industrial production units such as those of BP, Eastman Chemical, and DuPont still employ this process [83]. However, some inventions have been introduced and patented to improve and as a prospective replacement to AMOCO commercial process. As discussed previously, the AMOCO process offers a high yield of terephthalic acid production. But the process also causes severe environmental problems and safety issues particularly with the utilisation of the bromide ion that leads to the formation of methyl bromide, $\mathrm{CH}_{3} \mathrm{Br}$. This compound is very toxic and causes destruction of stratospheric ozone [84]. Therefore, a less hazardous method of oxidation of para-xylene to terephthalic acid is still sought by many researchers.

The combination of palladium with antimony or gold to oxidise para-xylene to terephthalic acid in the liquid phase has been studied. The process utilises oxygen and water as oxidant and solvent, respectively. The ratios of palladium to antimony and water to para-xylene were 10:1 and 30:1, respectively, while the oxidation temperature was $170{ }^{\circ} \mathrm{C}$. The advantages of this process are (1) it reduces reactor corrosion, (2) it provides a less hazardous para-xylene to terephthalic acid production as bromine is not used, and (3) the yield of terephthalic acid is high, i.e., $88.8 \%$ in $5 \mathrm{~h}$. On the other hand, the elimination of bromine in $\mathrm{Co} / \mathrm{Mn} / \mathrm{Br}$ (AMOCO process) is not relevant to the industrial production as this process produces low yields, i.e., < $30 \%$ [85].

Some researchers have also studied the feasibility of using renewable sources such as starch, sugar, and cellulose to produce para-xylene before it is oxidised to terephthalic acid. The renewable source is converted to 2,5-dimethylfuran (DMF) before being converted to para-xylene via Diels-Alder cycloaddition of ethylene. However, there is a complication in this conversion process as polymerisation takes place and reduces the amount of DMF. In the reaction, the DMF is polymerised to 2,5-hexadione (HD). As a result, the yield of para-xylene becomes less and this affects terephthalic acid production as well [86].

Specifically, the catalyst used in para-xylene conversion using renewable sources is $\mathrm{CuCI}_{2}$, with $88.3 \%$ yield. The conversion process is conducted at $250{ }^{\circ} \mathrm{C}$ and 250 psig of ethylene, and the reaction time is $7 \mathrm{~h}$. The para-xylene produced is oxidised to terephthalic acid using copper acetate and copper acetylacetonate, with $85.9 \%$ and $80.1 \%$ conversion process, respectively $[86,87]$. However, even though this process successfully produced para-xylene and terephthalic acid from biomass, this process requires a high cost due to the utilisation of 
ethylene. Another disadvantage is that the reaction is an inconvenient process. These factors make the use of renewable sources in the production of terephthalic acid not practical for the industrial scale.

The Mitsubishi decarbonylation and modification of the Henkel process can also produce terephthalic acid. The Mitsubishi decarbonylation process is conducted as a liquid phase air oxidation to convert para-xylene to terephthalic acid. Water is used as a solvent and the temperature is $250-300{ }^{\circ} \mathrm{C}$. Palladium on carbon is the catalyst, and the main reaction is the decarbonylation of 4-CBA to terephthalic acid. As for the modification of the Henkel process, this process is started once dipotassium terephthalate undergoes crystallisation from its aqueous solution. Then, activated carbon is introduced to remove coloured impurities that is the main problem in this reaction. Finally, sulfuric acid is added to produce fine crystals of terephthalic acid. Although these two processes can produce terephthalic acid, the use of more than two stages makes them intricate (www.sbioinformatics.com; accessed on 24 June 2014).

Therefore, industrial production units still have not found the best replacement for the commercial AMOCO process. The efforts to replace the AMOCO process suffer from problems including (1) application of expensive catalysts such as a noble metal catalyst and gold, (2) application of expensive chemicals such as ethylene, (3) non-environmental friendly reaction condition, and (4) application of another promoter to replace bromine such as NHPI adds to the operational cost as when a sacrificial promoter is used, it is consumed in the reaction. Besides, this promoter also has a low solubility in the acetic acid medium, thus making it quite less practical for industrial application [85]. Therefore, a method that can oxidise para-xylene to terephthalic acid with $>80 \%$ yield without environmental problems and safety issues is still under search, and more comprehensive studies are needed.

\section{Statistical modeling of para-xylene oxidation based on optimisation design}

The optimisation of para-xylene oxidation can be defined as an amount of reactant, catalyst, and other components that contribute in the oxidation of para-xylene to terephthalic acid. Any condition that can maximise the yield of terephthalic acid can be called an optimised condition. Other than that, some literature claims that optimisation is a reaction condition that deals with reducing costs while still maintaining the quality product [26].

Therefore, the main aims of the industrial optimisation of para-xylene oxidation are to minimise the content of 4-CBA in the crude terephthalic acid and to maximise the production rate with an acceptable operational cost. There are some efforts in modelling the optimisation of para-xylene oxidation. The efforts focus on the prediction of the 4-CBA content in the product using Multivariate Statistically Process Models to predict the 4-CBA content $[88,89]$. This model is based on the regression of process variable data. Other models such as Fuzzy Neural Network, Fuzzy Support Vector Regression Model, and
Fuzzy Adaptive Immune Algorithm have also been used [90-92]. All these modellings give the same individual trends as the result from the experiments. Thus, one or more variable from these models are manipulated individually or in sequence. As a result, a model that can predict a set of information regarding (1) catalyst concentration or proportion, (2) temperature, (3) pressure, (4) amount of solvent, (5) concentration of reactant, and (6) time, can be obtained and proved by experiment.

The experimental design in the oxidation of para-xylene can also be conducted using the Response Surface Methodology (RSM). RSM provides both the experimental design and the process optimisation based on the mathematical and statistical model. The Box-Behnken Design (BBD) and Central Composite Design (CCD) are the most common and suitable for the process optimisation [93-98]. However, BBD is more well known than CCD for the ability to predict and determine the optimal condition in the least number of experiments [99-104]. On the other hand, CCD also has the same function as BBD, but the latter demands more experiments as it studies the axial points of the parameters.

Overall, there are four steps in BBD and CCD in optimising the parameters of the components as follows: (1) BBD or CCD generates a set of experiments for the adequate and reliable measurement of the response, i.e., the production of terephthalic acid. During this step, a series of experiments generated by the design must be conducted to get the experimental values of the response. (2) A mathematical model of the second-order response surface is developed with the best fit. Then, the expected response value is obtained. (3) The optimal set of experiments that gives the best response value is determined. (4) Three-dimensional (3D) plots are generated to represent the interactive effect among the process parameters together with verification of the model and predictions.

As the statistical model is used to predict maximum response, verification is also conducted based on the statistical model. Specifically, the generated polynomial equation from the modelling is verified using the analysis of variance (ANOVA) at the 95\% confidence level. The verification by ANOVA is illustrated in Fig. 3. The model must be significant with a $p$-value less than 0.05 at the $95 \%$ confidence level applied in this statistical prediction. The insignificant lack of fit is important to support the model in the prediction process.

Generally, the correlation between the experimental and predicted data can be studied through a plot of predicted vs actual and a normal plot of residuals. These plots should give a linear pattern to show that there is no abnormality in both the experimental and predicted data. In addition, the differences between the experimental and predicted data can be calculated from Diagnostics Case Statistics data in ANOVA, and the differences should be less than $5 \%$. Otherwise, the differences are said to be significant, and the prediction is doubtful. On top of that, the prediction obtained must be proved by experiment. Therefore, it can be concluded that the optimisation by any optimisation designs such as CCD and BBD is beneficial in terms of less time consumption, ability to provide statistical verification, and ability to control the desired parameter range 


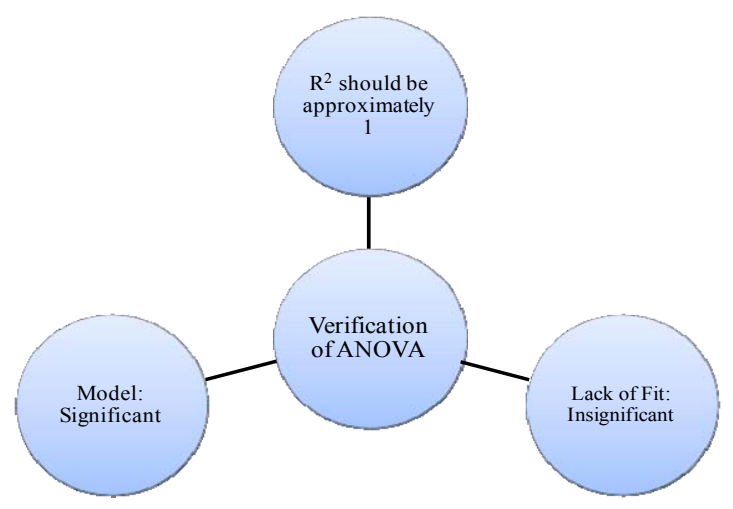

Fig. 3. Analysis of variance (ANOVA) to verify the optimisation of Central Composite Design (CCD) and Box-Behnken Design (BBD).

values. Thus, the aim to design an experimental reaction condition at an optimum level can be achieved.

\section{Summary and perspective}

This paper reviewed the production of terephthalic acid from the oxidation of para-xylene. The oxidation of para-xylene was reviewed for both noncatalytic and catalytic processes. The driving forces for para-xylene oxidation are the defects in the commercial AMOCO (Co/Mn/Br) process. Even though the AMOCO commercial process is impressive, the inconvenient nature of its components together with unsatisfactory severe reaction conditions demand more studies to find better reaction conditions. It would be impressive if a study can develop the oxidation of para-xylene under a solvent-free condition. The feasibility of a solvent-free condition for the oxidation of xylene derivatives has been demonstrated by the authors, which proved the feasibility of a solvent-free condition in the oxidation of para-xylene [43]. However, this condition is challenging and has a practicability issue as the product formed is in the solid phase. Therefore, the engineering modification of the reactor should be studied to offer a solvent-free condition due to the engineering and process restrictions. At present, it is important to test the feasibility and performance of para-xylene oxidation to terephthalic acid with a truly heterogeneous catalytic system and near-green reaction conditions with $\mathrm{CO}_{2}$ as the sole oxidant. The heterogeneous catalyst should be a hybrid catalyst with no expensive materials such as noble metal catalysts. The catalyst of iron-oxalate encapsulated in zeolite may be worthwhile considering as a replacement for the AMOCO commercial process.

\section{References}

[1] Li M, Niu F, Zuo X, Metelski P D, Busch D H, Subramaniam B. Chem Eng Sci, 2013, 104: 93

[2] Partenheimer W. Catal Today, 1995, 23: 69

[3] Wang L J, Cheng Y W, Wang Q B, Li X. Front Chem Eng China, 2007, 1: 317

[4] Giacomo C, Silber P. Ber Deutsch Chem Ges, 1912, 45: 38

[5] Xiao Y, Zhang X Y, Wang Q B, Tan Z, Guo C C, Deng W, Liu Z G, Zhang H F. Chin Chem Lett, 2011, 22: 135

[6] Stephens H N. JAm Chem Soc, 1926, 48: 2920

[7] Scheirs J, Long T E. Modern Polyesters: Chemistry and Technology of Polyesters and Copolyesters. Chichester: Wiley, 2013. 67

[8] Raghavendrachar P, Ramachandran S. Ind Eng Chem Res, 1992, 31: 453

[9] Saffer A, Barker R S. GB Patent 807091. 1959

[10] Whinfield J R, Dickson J T. GB Patent 578079. 1946

[11] Saffer A, Barker R S. US Patent 2833816. 1958

[12] Saffer A, Barker R S. US Patent 3089906. 1963

[13] Landau R, Saffer A. Chem Eng Progr, 1968, 64: 20

[14] Ghiaci M, Mostajeran M, Gil A. Ind Eng Chem Res, 2012, 51: 15821

\section{Graphical Abstract}

Chin. J. Catal., 2014, 35: 1641-1652 doi: 10.1016/S1872-2067(14)60193-5

\section{A brief review of para-xylene oxidation to terephthalic acid as a model of primary $\mathrm{C}-\mathrm{H}$ bond activation}

Nor Aqilah Mohd Fadzil, Mohd Hasbi Ab. Rahim*, Gaanty Pragas Maniam

Universiti Malaysia Pahang, Malaysia

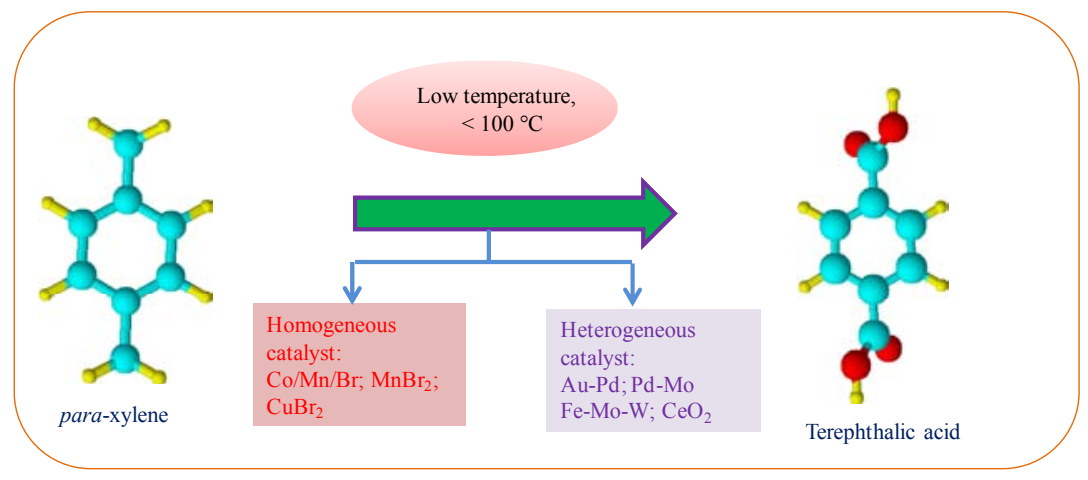

Developments in para-xylene oxidation to terephthalic acid were discussed, and environmental issues were emphasised together with prospective reaction condition optimisation. 
[15] Tomás R A F, Bordado J C M, Gomes J F P. Chem Rev, 2013, 113: 7421

[16] Li K T, Li S W. Appl Catal A, 2008, 340: 271

[17] Evans S, Lindsay Smith J R. J Chem Soc, Perkin Trans, 2000, 2: 1541

[18] Shaabani A, Rahmati A. Catal Commun, 2008, 9: 1692

[19] Gupta M, Paul S, Gupta R, Loupy A. Tetrahedron lett, 2005, 46: 4957

[20] Poling B E, Prausnitz J M, O'Connell J P. The Properties of Gases and Liquids. New York: McGraw-Hill, 2001. 28

[21] Savage P E. J Supercrit Fluids, 2009, 47: 407

[22] Dunn J B, Savage P E. Ind Eng Chem Res, 2002, 41: 4460

[23] Osada M, Savage P E. AIChE J, 2009, 55: 710

[24] Garcia-Verdugo E, Venardou E, Thomas W B, Whiston K, Partenheimer W, Hamley P A, Poliakoff M. Adv Synth Catal, 2004, 346: 307

[25] Garcia-Verdugo E, Fraga-Dubreuil J, Hamley P A, Thomas W B, Whiston K, Poliakoff M. Green Chem, 2005, 7: 294

[26] Fraga-Dubreuil J, Poliakoff M. Pure Appl Chem, 2006, 78: 1971

[27] Hamley P A, Ilkenhans T, Webster J M, Garcia-Verdugo E, Venardou E, Clarke M J, Auerbach R, Thomas W B, Whiston K, Poliakoff M. Green Chem, 2002, 4: 235

[28] Chavan S A, Srinivas D, Ratnasamy P. J Catal, 2001, 204: 409

[29] Sabater M J, Corma A, Domenech A, Forn'es V, Garcia H. Chem Commun, 1997: 1285

[30] Hutchings G J. Chem Commun, 1999: 301

[31] Falcon H, Campos-Martin J M, Al-Zahrani S M, Fierro J L G. Catal Commun, 2010, 12: 5

[32] Hermans I, Peeters J, Jacobs P A. Top Catal, 2008, 50: 124

[33] Frank C E. Chem Rev, 1950, 46: 155

[34] Russell G A. J Chem Educ, 1959, 36: 111

[35] Mayo F R. Acc Chem Res, 1968, 1: 193

[36] Ichikawa Y, Yamashita G, Tokashiki M, Yamaji T. Ind Eng Chem, 1970, 62(4): 38

[37] Fan J W, Zhang R Y.J Phys Chem A, 2006, 110: 7728

[38] Guo Z, Liu B, Zhang Q H, Deng W P, Wang Y, Yang Y H. Chem Soc Rev, 2014, 43: 3480

[39] Hronec M, Hrabe Z. Ind Eng Chem Prod Res Dev, 1986, 25: 257

[40] Jacob C R, Varkey S P, Ratnasamy P. Appl Catal A, 1999, 182: 91

[41] Tibbitt J M, Gong W H, Schammel W P, Hepfer R P, Adamian V, Brugge S P, Metelski P D, Zhou C X. WO Patent 133976 A2. 2007

[42] Kesavan L, Tiruvalam R, Ab Rahim M H, bin Saiman M I, Enache D I, Jenkins R L, Dimitratos N, Lopez-Sanchez J A, Taylor S H, Knight D W, Kiely C J, Hutching S G J. Science, 2011, 331: 195

[43] Ab Rahim M H, Forde M M, Jenkins R L, Hammond C, He Q, Dimitratos N, Lopez-Sanchez J A, Carley A F, Taylor S H, Willock D J, Murphy D M, Kiely C J, Hutching S G J. Angew Chem Int Ed, 2013, 52: 1280

[44] Ab Rahim M H, Forde M M, Hammond C, Jenkins R L, Dimitratos N, Lopez-Sanchez J A, Carley A F, Taylor S H, Willock D J, Hutchings G J. Top Catal, 2013, 56: 1843

[45] Deori K, Gupta D, Saha B, Awasthi S K, Deka S. J Mater Chem A, 2013, 1: 7091

[46] Qin Z Z, Su T M, Jiang Y X, Ji H B, Qin W G. Chem Eng J, 2014, 242:414

[47] Liu H L, Li Y W, Jiang H F, Vargas C, Luque R. Chem Commun, 2012, 48: 8431

[48] Della Pina C, Falletta E, Rossi M. Chem Soc Rev, 2012, 41: 350

[49] Khan N A, Kennedy E M, Dlugogorski B Z, Adesina A A, Stockenhuber M. Catal Commun, 2014, 53: 42

[50] Impeng S, Khongpracha P, Warakulwit C, Jansang B, Sirijaraensre J, Ehara M, Limtrakul J. RSC Adv, 2014, 4: 12572

[51] Liu H L, Chen G Z, Jiang H F, Li Y W, Luque R. ChemSusChem, 2012,
5: 1892

[52] Sheehan R J. Terephthalic Acid, Dimethyl Terephthalate, and Isophthalic Acid. Wiley-VCH, 2002. 156

[53] Shigeyasu M, Kusano N. US Patent 4160108. 1979

[54] Seko M, Miyake T, Takeuchi H, Tanouchi M. US Patent 4230882A. 1980

[55] Scott L S, Sommers R W. US Patent 158738. 1979

[56] Kahsar K R, Schwartz D K, Medlin J W. J Am Chem Soc, 2014, 136: 520

[57] Bramucci M G, McCutchen C M, Nagarajan V, Thomas S M. Google Patents, 2002

[58] Bramucci M G, McCutchen C M, Nagarajan V, Thomas S M. US Patent 0170836. 2003

[59] Robert R, Ratnasamy P. J Mol Catal A, 1995, 100: 93

[60] Mäki-Arvela P, Kumar N, Nasir A, Salmi T, Murzin D U. Ind Eng Chem Res, 2005, 44: 9376

[61] Marimuthu A, Zhang J W, Linic S. Science, 2013, 339: 1590

[62] Lee I, Delbecq F, Morales R, Albiter M A, Zaera F. Nat Mater, 2009, 8: 132

[63] Wang Y, Zhang S J, Zhao Y X, Lin M. J Mol Catal A, 2014, 385:1

[64] Yoo J S, Jhung S H, Lee K H, Park Y S. Appl Catal A, 2002, 223: 239

[65] Zuo X B, Niu F H, Snavely K, Subramaniam B, Busch D H. Green Chem, 2010, 12: 260

[66] Zuo X B, Subramaniam B, Busch D H. Ind Eng Chem Res, 2008, 47: 546

[67] Park S E, Yoo J S. Stud Surf Sci Catal, 2004, 153: 303

[68] Jhung S H, Park Y S, Lee K H, Chae J H, Yoo J S. WO Patent 037407Al. 2000

[69] Raju G, Reddy B M, Park S E. Indian J Chem A, 2012, 51: 1315

[70] Ali A M, Emanuelsson E A C, Patterson D A. Appl Catal B, 2010, 97: 168

[71] Wang S B, Zhu Z H. Energy Fuels, 2004, 18: 1126

[72] Yan N, Fu X Z, Chuang K T, Luo J L.J Power Sources, 2014, 254: 48

[73] Ma Z, Zaera F. Encyclopedia of Inorganic and Bioinorganic Chemistry. Hoboken, New Jersey: John Wiley and Sons, 2014. 418

[74] Pakhare D, Spivey J. Chem Soc Rev, 2014

[75] Ansari M B, Park S E. Energy Environ Sci, 2012, 5: 9419

[76] Brill W F. Ind Eng Chem, 1960, 52:837

[77] Tashiro Y, Iwahama T, Sakaguchi, Ishii Y. Adv Synth Catal, 2001, 343: 220

[78] Coseri S. Catal Rev-Sci Eng, 2009, 51: 218

[79] Xu H F, Tang R R, Gong N H, Liu C H, Zhou Y P. Progr Chem, 2007, 19: 1736

[80] Saha B, Koshino N, Espenson J H.J Phys Chem A, 2004, 108: 425

[81] Cheng Y W, Li X, Wang L J, Wang Q B. Ind Eng Chem Res, 2006, 45: 4156

[82] Cao N, Chang E, Kaufman M. Senior Design Report. University of Pennsylvania, 2011

[83] Zhang Y, Feng J, Lyu Z, Li X. Modern Res Catal, 2014, 3: 19

[84] Horst A, Holmstrand H, Andersson P, Thornton B F, Wishkerman A, Keppler F, Gustafsson 0. Geochim Cosmochim Acta, 2014, 125 : 186

[85] Schammel W P, Huggins B J, Kulzick M A, Nubel P O, Rabatic B M, Zhou C X, Adamian V A, Gong W H, Metelski P D, Miller J T. US Patent 8624055. 2014

[86] Masuno M N, Smith P B, Hucul D A, Dumitrascu A, Brune K, Smith R L, Bissell J, Foster M. US Patent 0245316 A1. 2013

[87] Pacheco J J, Davis M E. Proceedings of the National Academy of Sciences of USA. 2014. 345

[88] Han I S, Kim M, Han C. Theor Appl Chem Eng, 2002, 8: 2989

[89] Han I S, Kim M, Lee C H, Cha W, Ham B K, Jeong J H, Lee H, Chung C B, Han C. Korean J Chem Eng, 2003, 20: 977 
[90] Liu R L, Su H Y, Mu S J, Jia T, Chen W Q, Chu J. Chin J Chem Eng, 2004, 12: 234

[91] Zhan Y, Su H Y, Liu R L, Chu J. Chin J Chem Eng, 2005, 13: 642

[92] He H, Du W L, Qian F, Zhong W M. Ind Eng Chem Res, 2010, 49: 5683

[93] Makareviciene V, Skorupskaite V, Levisauskas D, Andruleviciute V, Kazancev K. Int J Green Energy, 2014, 11: 527

[94] Rasouli F, Aber S, Salari D, Khataee A R. Appl Clay Sci, 2014, 87: 228

[95] Salman J M. Arabian J Chem, 2014, 7: 101

[96] Roosta M, Ghaedi M, Daneshfar A, Darafarin S, Sahraei R, Purkait M K. Ultrason Sonochem, 2014, 21: 1441
[97] Torrades F, García-Montaño J. Dyes Pigments, 2014, 100: 184

[98] Wang S, Liu H P, Zhang Y, Yu J, Yuan W. Appl Mechanics Mater, 2014, 464: 77

[99] Pasma S A, Daik R, Maskat M Y, Hassan O. Int J Polym Sci, 2013, 10:1

[100] Körbahti B K, Rauf M A. Chem Eng J, 2008, 136: 25

[101] Jeganathan P M, Venkatachalam S, Karichappan T, Ramasamy S. Preparative Biochem Biotechnol, 2014, 44: 56

[102] Sharif K M, Rahman M M, Azmir J, Mohamed A, Jahurul M H A, Sahena F, Zaidul I S M. J Food Eng, 2014, 124: 105

[103] Grilc M, Likozar B, Levec J. Appl Catal B, 2014, 150-151: 275

[104] Mujtaba A, Ali M, Kohli K. Chem Eng Res Des, 2014, 92: 156 